\title{
O processo de trabalho na assistência ao parto em Londrina-PR
}

\author{
THE WORKING PROCESS IN LABOR CARE IN LONDRINA-PR
}

EL PROCESSO DE TRABAJO EN LAASISTENCIA DEL PARTO EN LONDRINA-PR

Thelma Malagutti Sodré1, Rúbia Aparecida Lacerda²,

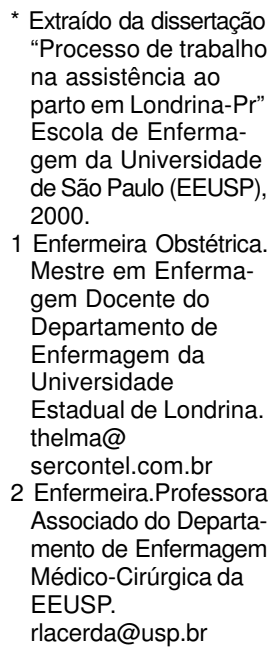

1 Enfermeira Obstétrica. Mestre em Enferma-

gem Docente do

Departamento de

Enfermagem da

Universidade

Estadual de Londrina. thelma@

sercontel.com.br

2 Enfermeira.Professora

Associado do Departa-

mento de Enfermagem

Médico-Cirúrgica da

EEUSP

rlacerda@usp.br

\section{RESUMO}

Neste estudo investigamos a assistência ao trabalho de parto no município de Londrina-PR, sob o recorte da decisão dos profissionais em prescrever jejum, enema e tricotomia. Os dados foram colhidos em cinco instituições, por meio de entrevistas com dez médicos obstetras, oito enfermeiras e uma obstetriz, em 2000. As entrevistas foram interpretadas por meio da análise do discurso, extraindo-se frases temáticas. O referencial teórico utilizado foi o materialismo histórico e dialético. A análise das frases identificou o processo de trabalho dessa assistência com seus elementos constituintes. O médico é o principal agente e único com poder de decisão. Tal poder é reforçado pelos instrumentos identificados - a prescrição médica, o trabalho das enfermeiras e o local de prática: o hospital. O saber que embasa essa prática é o modelo clínico, representado pelas intervenções não individualizadas que atendem antes às necessidades dos agentes do que às do seu objeto (a parturiente).

\section{DESCRITORES}

Enfermagem obstétrica.

Trabalho de parto.

Processos de enfermagem.

\section{ABSTRACT}

In this study, delivery care in the city of Londrina, State of Paraná, was investigated under the focus of health professionals' decisions to prescribe procedures such as fasting, enema and trichotomy. The theoretical referential was historical and dialectical materialism. The data survey was carried out in 2000 in five institutions and included individual interviews with ten obstetricians, eight nurses and one midwife. The interviews were interpreted using the speech analysis and then the thematic phrases were extracted. It was possible to identify the working process and its constitutive elements. The physician is the only one with decision power. Such power is reinforced by the following instruments identified in the study: medical prescriptions, nursing staff's work and the place where it is practiced-the hospital. The knowledge that supports this practice is the clinical model, represented by non-individualized interventions that focus more on the agents' needs than on their object's (the parturient).

\section{KEY WORDS}

Obstetricial nursing.

Labor, obstetric.

Nursing process.

\section{RESUMEN}

En este estudio investigamos la asistencia al trabajo de parto en el municipio de Londrina-PR, bajo el recorte de la decisión de los profesionales en prescribir ayuno, enema y tricotomía. Los datos fueron cogidos en cinco instituciones, por medio de entrevistas a diez médicos obstetras, ocho enfermeras y una obstetriz, en el año 2000. Las entrevistas fueron interpretadas por medio del análisis del discurso, extrayéndose frases temáticas. El referencial teórico utilizado fue el materialismo histórico y dialéctico. El análisis de las frases identificó el proceso de trabajo de esa asistencia con sus elementos constitutivos. El médico es el principal agente, y único con poder de decisión. Tal poder es reforzado por los instrumentos identificados - la prescripción médica, el trabajo de las enfermeras y el local de práctica: el hospital. El saber en que se fundamenta esa práctica es el modelo clínico, representado por las intervenciones no individualizadas que atienden antes a las necesidades de los agentes que a las de su objeto (la parturienta).

\section{DESCRIPTORES}

Enfermería obstétrica.

Trabajo de parto.

Procesos de enfermería. 


\section{INTRODUÇÃO}

Ficamos sempre maravilhados ao lembrar que o parto, uma experiência milenar, ocorria no cenário caloroso das próprias casas das mulheres. Como experiência familiar podemos relatar que nossas avós eram acompanhadas por parteiras, e que seus maridos ajudavam a aparar o próprio filho. A atitude expectante da parteira respeitava o ritual de vida de nossas famílias. Ela era respeitada pela sua arte de partejar e também pela sua presença amigável durante o parto, oferecendo segurança e principalmente participando de tudo que foi planejado e preparado com tanto entusiasmo e afeto.

No século XX esta cena foi transferida para o espaço hospitalar, com todas as condições propícias para a prática de rotinas cirúrgicas, como a episiotomia e o fórcipe profilático, afastando a parteira da arte de partejar.

Estas mudanças no modelo de assistência ao parto e ao nascimento perduram até os dias de hoje. Consolidaram-se com a substituição da casa pelo hospital e da parteira pelo médico; a transformação de um modelo feminino de atenção em um modelo masculino; aceitação de uma série de regras em nome da segurança da mulher, do filho e do atendimento médico. Na configuração histórica do parto os recursos técnicos eram reforçados em detrimento dos direitos humanos à condição de pessoa, à integridade corporal e à eqüidade ${ }^{(1)}$.

Podemos lembrar das múltiplas vezes em que os anseios e ritmos naturais da mulher não receberam prioridade e a despersonalizamos em nossos serviços, quando autoritariamente a despimos, raspamos seus pêlos, limpamos seu intestino com um enema, instalamos um soro e a deixamos afastada da família.

Compreendemos que tais intervenções são efetuadas sob dados modelos tecnológicos, configurando processos de trabalho, ou aquilo que é denominada de ações tecnoassistenciais, isto é,

...ações que expressam uma dada construção do que é o objeto saúde-doença, expressando uma maneira particular de organizar a produção destas ações como serviços ${ }^{(2)}$.

Nesse contexto, encontramos um suporte na Organização Mundial da Saúde que, ao perceber que havia uma tendência em tratar rotineiramente todos os partos e nascimentos como se tivessem risco e que o binômio mãe e filho poderia ser prejudicado através de práticas desnecessárias, publicou, em 1996, o Manual Assistência ao Parto Normal: um guia prático, como referência para a implantação do parto humanizado nos serviços de saúde. Esse guia discute as práticas obstétricas vigentes e recomendadas, com base em evidências científicas e classifica as mesmas em quatro categorias, dependendo de sua utilidade, eficácia e ausência de periculosidade ${ }^{(3)}$.

Esse manual da Organização Mundial da Saúde intensificou nossa intenção de pesquisar e discutir sobre as rígidas rotinas que tratam a parturiente, bem como direcionou a seleção das práticas de assistência ao trabalho de parto consideradas inadequadas, prejudiciais ou ineficazes que pretendíamos estudar.

Adotamos como objeto deste estudo a análise da qualidade da assistência ao trabalho de parto, compreendendo que essa assistência se realiza através de processos de trabalho, os quais, por sua vez, inserem-se em um dado momento histórico de desenvolvimento social e de compreensão do processo saúde-doença. Em princípio, consideramos, neste estudo, que a qualidade de um processo de trabalho de assistência à parturiente, ainda que efetivado sob uma dada estrutura de necessidades sociais, deve atender às necessidades individuais de cada mulher e não às necessidades dadas apenas pelos sujeitos e suas instituições.

Para tanto, torna-se imprescindível reconhecer o processo de trabalho que se efetiva para a assistência ao trabalho de parto, identificando seus elementos constituintes (objeto, agentes, instrumentos e finalidade) e sua relação com as circunstâncias atuais de organização de assistência ao processo saúde-doença.

Os objetivos deste estudo foram: a) conhecer as justificativas dos profissionais de saúde para a realização de práticas de intervenção na assistência ao trabalho de parto em maternidades de Londrina; b) identificar os processos de trabalho que embasam a assistência ao parto, a partir das justificativas apresentadas pelos profissionais.

\section{PERCURSO METODOLÓGICO}

Optamos pela pesquisa qualitativa, pautada no método materialista histórico e dialético, sob as seguintes categorias de análise: Processo de Trabalho e Necessidades. O referencial teórico adotado baseia-se na análise de práticas em saúde ${ }^{(4)}$, que qual parte do referencial de processo de trabalho e de valorização de $\operatorname{Marx}^{(5)}$ e da teoria das necessidades de Heller ${ }^{(6)}$.

A população foi composta por médicos obstetras, enfermeiras e uma obstetriz, que assistiam às parturientes. Do total de seis instituições hospitalares que prestavam assistência ao parto em Londrina-Pr, participaram duas públicas, duas privadas e uma beneficente. Houve aprovação do Comitê de Ética em Pesquisa da Universidade Estadual de Londrina para o desenvolvimento das pesquisas. Os critérios 
adotados para a seleção desta amostra pautaram-se nos referenciais teóricos de Minayo ${ }^{(7)}$ e na organização da análise apresentada por Bardin ${ }^{(8)}$.

Os dados subjetivos, relacionados aos valores, às atitudes e às opiniões dos sujeitos desta pesquisa, foram coletados através de entrevista a partir da seguinte questão norteadora: Descreva com o máximo possível de detalhes como você decide a prescrição de jejum, enema e retirada de pêlos para uma parturiente.

A seleção destas práticas de assistência ao trabalho de parto pautou-se no documento da $\mathrm{OMS}^{(3)}$, que classifica a restrição hídrica e alimentar durante o trabalho de parto como prática frequientemente utilizada de modo inadequado e o uso rotineiro de enema e tricotomia como práticas claramente prejudiciais ou ineficazes e que devem ser eliminadas.

As entrevistas foram realizadas nos meses de janeiro e fevereiro de 2000, com uma duração que variou de 4 a 25 minutos. Nelas, buscamos o maior número possível de representação de todas as instituições no período de coleta de dados, totalizando trinta e oito profissionais, sendo vinte e sete médicos obstetras, dez enfermeiras e uma obstetriz. Proporção essa compatível com a distribuição da presença desses profissionais nas instituições. Desse total, foram selecionadas para a análise do discurso dezoito entrevistas, das quais dez foram com médicos obstetras, sete com enfermeiras e uma com uma obstetriz.

Os critérios para essa seleção pautaram-se inicialmente na possibilidade de detectar se todas as entrevistas abrangiam a historicidade do objeto de estudo, sua localização no modo de produção, que é a totalidade maior, a cultura de classes e as representações sociais como expressões do lugar e das condições sociais de trabalho dos sujeitos em questão $^{(7)}$. Acatamos também a organização da análise, a qual se desdobra em três etapas, a saber: a pré-análise, a exploração do material e o tratamento dos resultados, a inferência e a interpretação ${ }^{(8)}$.

Aplicamos, em primeira instância e, em todas as entrevistas obtidas, a etapa de pré-análise, ou seja, a fase de organização propriamente dita, quando foi inicialmente realizada a leitura flutuante, que é o contato exaustivo com o material coletado, através da transcrição das entrevistas e sua leitura repetida, com o objetivo de categorizá-las, e depois realizamos a escolha dos documentos, que é a constituição do corpus do estudo, ou seja, o conjunto dos documentos a serem analisados, que foi composto pelas entrevistas na íntegra, sob algumas regras: - exaustividade: todas as entrevistas foram transcritas, uma vez que todas elas são consideradas como elementos desse corpus; - representatividade: todas as instituições que aceitaram participar deste estudo apresentavam profissionais médicos obstetras e enfermeiros que decidem sobre a prescrição do jejum, enema e retirada de pêlos para uma parturiente.
Assim, todas elas foram contempladas, com exceção de apenas uma, que não apresentava enfermeiras que participavam diretamente da decisão de procedimentos de assistência ao parto, em função das características próprias da instituição, as quais não foram entrevistadas;- homogeneidade: todos os profissionais foram submetidos à mesma entrevista, ou seja, sob os mesmos critérios quanto ao tema, a técnica e os interlocutores; - pertinência: todos os dados coletados foram pertinentes ao objetivo proposto neste estudo.

Após a verificação de que todas as entrevistas transcritas contemplavam os critérios acima relacionados, selecionamos dois discursos de médicos de cada uma das cinco instituições (total de dez) e dois de profissionais de enfermagem de quatro instituições (sendo sete enfermeiras e uma obstetriz), sendo que as enfermeiras de uma das instituições não participavam do processo de assistência direta ao trabalho de parto. Nesse processo de seleção buscamos também a maior variedade possível de discursos que justificavam de formas favoráveis e desfavoráveis à realização dos procedimentos de assistência previamente selecionados.

As entrevistas foram submetidas à Análise de Discurso. Para tanto, elas foram gravadas, transcritas e tratadas com uma técnica de depreensão de frases temáticas ${ }^{(9-10)}$, resultando em unidades de significados, ou categorias e subcategorias empíricas. A primeira categoria denominou-se DECIDINDO PELA MULHER, com as subcategorias: $A$ voz do médico e $A$ voz da enfermeira. A segunda denominou-se FINALIDADE X NECESSIDADE, com as subcategorias (Des) fundamentação científica e Viés da cesárea.

A primeira categoria empírica refere-se à tomada de decisão dos profissionais para a realização dos procedimentos selecionados nesse estudo e a segunda às justificativas para a sua realização. Os fatos mais significativos dessas categorias são apresentados com as frases temáticas inerentes aos temas abordados, buscando articulá-las com as categorias de análise.

Cada frase está acompanhada por uma letra $\mathrm{M}$, que corresponde ao discurso de um médico ou $\mathrm{E}$, ao de uma enfermeira, seguido de um número para simples organização seqüencial das entrevistas. A letra I, acompanhada de um número, identifica a instituição na qual o profissional estava inserido. A sigla TP, utilizada em quase todos os discursos, significa Trabalho de Parto.

\section{RESULTADOS}

\section{Categoria Decidindo pela mulher}

Subcategorias: A voz do médico e A voz da enfermeira.

Nesta categoria foi possível reconhecer como o processo de trabalho em saúde conduz a assistência à parturiente, 
pela identificação dos seus elementos constituintes. Assim, o agente executor deste processo é o médico, tendo a parturiente como objeto de sua assistência. As prescrições rotineiras, não individualizadas, verbais ou escritas e o processo de trabalho das enfermeiras constituem os instrumentos deste processo de trabalho de assistência ao parto.

O modelo tecno-assistencial que embasa tais práticas obstétricas é o clínico biológico. Assim sendo, todas as parturientes são submetidas a prescrições rotineiras de jejum, enema e retirada de pêlos. Sendo o médico o agente condutor deste processo de trabalho, é ele que exclusivamente prescreve todos os procedimentos. As prescrições generalizadas de jejum, enema e retirada de pêlos denotam a falta de embasamento científico sobre a necessidade de tais procedimentos, cuja tomada de decisão pelo médico é influenciada pela sua formação acadêmica tradicional. O que norteia suas ações é a possibilidade sempre presente de intercorrências durante o trabalho de parto. A assistência é massificada e autoritária; as mulheres se relacionam com o saber médico de forma passiva e submissa, sendo sempre denominada de pacientes, o que reforça a conotação de agente passivo sobre seu próprio corpo.

Algumas frases temáticas que permitiram tais resultados são:

- Este médico prescreve a retirada de pêlos mais por um desencargo de consciência, por ter aprendido que não é possível fazer uma adequada assepsia da paciente para o parto normal sem a retirada dos pêlos. (M-5; I-3)

- Esta enfermeira refere que os médicos continuam prescrevendo a tricotomia, mesmo sem fundamentar cientificamente sua conduta, porque aprenderam desta forma. (E-7; I-5)

- Este médico prescreve tricotomia para todos os partos normais. (M-5; I-3)

- O fleet enema é prescrito para todas as pacientes. (M-6; I-3)

- Esta enfermeira afirma que $90 \%$ dos médicos prescrevem jejum, fleet enema e retirada de pêlos. (E-3; I-1)

- Nesta instituição, jejum absoluto, enema e tricotomia são prescritos de rotina para todas as pacientes. (E-7; I-5)

- Nesta instituição, jejum absoluto, enema e tricotomia são prescritos de rotina para todas as pacientes. (E-7; I-5)

- Este médico prescreve o jejum para evitar a aspiração, porque paciente com contração vomita se estiver com estômago cheio. (M-8; I-2)

- Nem a água é liberada à paciente no final do TP. $(\mathrm{E}-4 ; \mathrm{I}-4)$
Alguns profissionais expressaram a preocupação com os desconfortos físicos da parturiente e a possibilidade dela ter direito a tomar decisões. Frases temáticas que permitiram tal conclusão:

- Este médico não interfere na decisão da paciente pela depilação. (M-4; I-1)

- Este médico sente mais segurança com o uso do tricótomo do que com o da lâmina, por não provocar escarificação da pele. (M-5; I-3)

A decisão, sendo centrada na figura hegemônica do poder/saber do médico faz com que as enfermeiras permaneçam submissas aos critérios e prescrições médicas, fazendo com que, por vezes, a relação médico obstetra-enfermeira seja conflitante e desarticulada. Conforme as falas de algumas enfermeiras: A voz do médico é a voz que tem a voz. A voz da enfermeira é a voz sem voz. A mulher é aquela que nada sabe. A seguir, outras frases temáticas dos discursos que possibilitaram estas afirmações.

- Esta enfermeira cumpre as condutas estabelecidas pelo médico, mesmo na ausência dele. (E-1; I-1) (E-2; I-3)

- A paciente chega à maternidade com uma prescrição médica exigindo seu cumprimento pela enfermeira. (E-3; I-1)

- As pacientes atendidas pelo plantão são avaliadas por esta enfermeira e o médico é quem decide a internação, após ser comunicado a distância por ela. (E-5; I-4)

-Esta enfermeira tem de seguir a prescrição médica. (E-7; I-5)

- Poucos médicos aceitam a argumentação da enfermeira para não realizar a poda de pêlos na multípara (...não abrem mão...).(E-1; I-1)

- Os questionamentos da enfermeira geram conflito com o médico. (E-3; I-1)

Apenas uma entrevistada afirmou que a enfermeira deve ser o agente decisor, apreendida pela frase temática:

- Esta enfermeira acredita que ela é o profissional que deve decidir pela prescrição ou não do jejum, enema e retirada de pêlos, pela sua capacidade de discernimento e por ela ser o profissional que acompanha o TP. (E-3; I-1)

Os profissionais expressaram a influência das rotinas institucionais informais no processo de decisão para a prescrição de cuidados e o médico ficou configurado como o cliente de fato do hospital, conforme as frases temáticas:

- Apesar deste médico achar desnecessária a poda total de pêlos, ele costuma agir conforme a rotina hospitalar. (M-3; I-1) 
- O enema é uma rotina da instituição (se a paciente estiver com até $7 \mathrm{~cm}$ de dilatação), que pode ser alterada pelo médico. $(\mathrm{E}-1 ; \mathrm{I}-1)$

- Todas as pacientes internadas nesta instituição ficam em jejum. Recebem só água, em pequena quantidade. (E-5; I-4)

- Nesta instituição, água e chá são liberados durante todo o TP. (E-8; I-3)

\section{Finalidade X Necessidade}

\section{Subcategorias: (Des) Fundamentação científica e Viés da cesárea.}

Nesta categoria foi possível identificar outros instrumentos do processo de trabalho na assistência ao parto utilizados pelo médico, quais sejam: a instituição e a parturiente. Ao assumir o controle total sobre a mulher, ele a transforma em instrumento de trabalho também. Tais situações denotam que uma das finalidades deste processo de trabalho é tratar o parto para atender às necessidades antes do profissional do que da própria parturiente.

A sub-categoria (Des) fundamentação científica é apreendida nas justificativas contraditórias, carência de fundamentação e critérios científicos e ausência de consenso quanto à necessidade da prescrição destes procedimentos.

Frases temáticas com justificativas favoráveis e desfavoráveis à realização destes procedimentos são as que seguem:

a) Favoráveis

- Jejum:

- O jejum é superimportante, porque a resolução do parto é imprevisível, além do risco de a paciente aspirar se vomitar. (M-7; I-1)

- O jejum é orientado por causa das náuseas e vômitos que a paciente pode ter durante as contrações. (E-4; I-4)

- Quando a paciente chega em fase adiantada do TP, jejum, enema e retirada de pêlos não são realizados. (E-2; I-3)

- O jejum total já não tem sido realizado. (M-3; I-1)

- Este médico veio de uma escola que sempre prescreveu o jejum, por causa da possibilidade de se fazer uma cesárea. (M-10; I-4)

- O fleet enema é prescrito para todas as pacientes somente para evitar o risco de contaminação da episiotomia. (M-5; I-3)

\section{- Tricotomia:}

- Como na maioria das pacientes é realizada a episiotomia, se houver evacuação, o risco de ocorrer uma infecção local é maior. (M-6; I-3)

- Se o enema não é realizado, certamente a paciente vai evacuar na sala de parto e contaminar a episiotomia e o campo. (M-8; I-2)

- A poda de pêlos é necessária para facilitar a sutura. (M-3; I-1)

- Esta enfermeira acha a tricotomia total desnecessária para o parto normal e prefere aparar os pêlos da região da episiotomia, para facilitar a visualização local durante a sutura e evitar infecção. (E-5; I-4)

- Enema:

- Esta enfermeira considera adequado fazer o enema porque ele estimula o TP, evita a eliminação de fezes e a contaminação. (E-6; I-5)

- O fleet enema é prescrito para todas as pacientes somente para evitar o risco de contaminação da episiotomia. (M-5; I-3)

- Como na maioria das pacientes é realizada a episiotomia, se houver evacuação, o risco de ocorrer uma infecção local é maior. (M-6; I-3)

- Se o enema não é realizado, certamente a paciente vai evacuar na sala de parto e contaminar a episiotomia e o campo. (M-8; I-2)

- Esta enfermeira considera adequado fazer o enema porque ele estimula o TP, evita a eliminação de fezes e a contaminação. (E-6; I-5)

b) Desfavoráveis

- Jejum

- Se a paciente tiver náusea e vômito, ela mesma vai evitar a ingesta dos líquidos.(M-3; I-1)

- As pacientes devem ser orientadas e estimuladas a ingerir líquidos e alimentos hipercalóricos e de fácil absorção. (M-2; I-2)

- O jejum prolongado oferece risco de hipoglicemia e desidratação, que pode diminuir o volume sanguíneo materno e favorecer o sofrimento fetal. (M-2; I-2)

- Enema

- A ocorrência de infecção por evacuação durante o TP questionável e não tem sido observada na prática. (M-1; I-2) 
- A evacuação no período expulsivo não interfere na incidência de infecção. (M-4; I-1)

- Para este médico, se no TP houver eliminação de fezes, é preferível que não sejam líquidas. (M-5; I-3)

- O enema só molesta as pacientes... é desconfortável e não traz benefício nenhum... (M-2; I-2)

- Tricotomia

- A depilação é desconfortável e desnecessária. (M-4; I-1)

- Não se orienta a retirada de pêlos porque favorece a colonização das bactérias presentes no local. (M-4; I-1)

- Quando os pêlos são raspados com lâmina ou depilados com cera, há sempre uma lesão da pele que favorece as infecções. (M-9; I-4)

- A tricotomia fere a pele, causa prurido e incômodo à parturiente. (M-2; I-2)

- A retirada de pêlos e o enema são procedimentos invasivos e aumentam a ansiedade da paciente. (E-1; I-1)

Alguns discursos, ainda que minoria, consideram a possibilidade de se analisar as parturientes caso a caso, ou de utilizar alternativas:

- Durante a episiotomia, os pêlos podem ser podados com tesoura na região da incisão. (M-2; I-2)

- Algumas vezes podem ser retirados os pêlos somente do local da episiotomia. (M-6; I-3)

- Esta enfermeira considera que, na multípara, possa ser realizada a poda de pêlos somente no períneo. (E-8; I-3)

- Este médico considera correto cortar os pêlos com tesoura ou tricótomo (...um pêlo de $1,0 \mathrm{~cm}$, de $0,5 \mathrm{~cm}$ não atrapalha nada.), para não lesar a pele, um pouco antes do parto ou da cesárea. (M-9; I-4)

O problema da ausência ou contradição na fundamentação científica torna-se muito claro nas frases temáticas que seguem:

- Este médico desconhece a literatura sobre as técnicas de retirada de pêlos e sua relação com a incidência de infecções. (M-1; I-2)

- Fazer tricotomia não aumenta nem diminui a infecção. $(\mathrm{M}-2 ; \mathrm{I}-2)$

- A realização ou não de jejum, enema e retirada de pêlos segue a formação acadêmica (prescrição clássica), sem embasamento na literatura. (M-1; I-2)

- Este médico prescreve a retirada de pêlos mais por um desencargo de consciência, por ter aprendido que não é possível fazer uma assepsia adequada da paciente para o parto normal sem a retirada dos pêlos. (M-5; I-3)

- Esta enfermeira refere que os médicos continuam prescrevendo a tricotomia, mesmo sem fundamentar cientificamente sua conduta, porque aprenderam desta forma. (E-7; I-5)

A sub-categoria viés da cesárea justifica a prática intervencionista da assistência ao parto, representada, aqui, pelos procedimentos de jejum, enema e retirada de pêlos. Conforme as frases temáticas:

- As pacientes que se submeterão a cesárea programada devem ficar em torno de oito horas em jejum para evitar aspiração. (M-7; I-1)

- Em casos de cesárea eletiva, a tricotomia pode ser feita no local da incisão. (M-8; I-2)

- Este médico veio de uma escola que sempre prescreveu o jejum por causa da possibilidade de se fazer uma cesárea. (M-10; I-4)

- Esta enfermeira explica à paciente que ela fica em jejum por causa da possibilidade de indicação de cesárea de urgência durante o TP. (E-5; I-4)

- O critério médico para a manutenção do jejum de todas as pacientes é a possibilidade de realização de cesárea. (M-1; I-2)

\section{DISCUSSÃO DOS DADOS}

As categorias empíricas obtidas dos discursos dos profissionais sobre a prescrição de enema, jejum e tricotomia em parturientes, aproximadas do referencial teórico adotado, permitiram identificar os processos de trabalho na assistência ao trabalho de parto na cidade de Londrina e validar as hipóteses inicialmente elaboradas.

Pode-se dizer, na verdade, que se configurou, em todas as instituições investigadas, um mesmo processo de trabalho, que se efetua através de um único modelo assistencial: o clínico, centrado na doença. Esse modelo toma o homem não em sua totalidade, mas reduzido ao corpo biológico e passível de intervenções diagnósticas e terapêuticas muitas vezes invasivas.

Em sua totalidade, compreendemos o homem além de seu corpo biológico, incluindo também seu corpo social e cultural, portanto, historicamente determinado e agente ativo das decisões sobre seu processo saúde-doença.

A identificação desse modelo de assistência ao trabalho de parto deu-se menos pelo fato de a maioria dos discursos serem favoráveis à realização desses procedimentos e mais pela não-individualização ou pela não-consideração desse objeto em sua totalidade. Assim, as decisões dos profis- 
sionais, mesmo quando não favoráveis a esses procedimentos, referiam-se às parturientes de forma geral, tomadas como corpos iguais, ou seja, objetos passivos de ações que não oferecem resistência.

Ao observar também que os discursos muitas vezes justificavam tais procedimentos pela eventualidade de intercorrências, principalmente a evolução para a cesárea, esse objeto de trabalho mostra-se ainda mais reduzido que aquele considerado no hospital em geral, na assistência aos doentes. Esse objeto não é o corpo biológico como um todo, cujos sinais e sintomas se devem avaliar previamente para a verificação de necessidades individuais de procedimentos, mas um corpo sempre passível de intercorrências. Portanto, de generalização de procedimentos.

O profissional médico emergiu como o principal agente desse processo, detendo o poder de decisão para sua efetivação. O trabalho da enfermeira apareceu subordinado ao do médico, evidenciando-se uma divisão técnica e social do trabalho de assistência ao parto, de cujas decisões a enfermeira não participa. Em outras palavras, o trabalho da enfermeira entra como instrumento do trabalho do médico.

Vale enfatizar que o aprofundamento da divisão técnica e social do trabalho faz com que produtos de alguns processos passem a ser objetos e meios (instrumentos) de outros processos de trabalho ${ }^{(4)}$. Poder-se-ia concluir, nesse caso, que essa subordinação deve-se ao fato de tais enfermeiras não serem especializadas em obstetrícia e tenderem a olhar a parturiente como o médico, sob o enfoque da doença. Portanto, não se oferece resistência e repete-se o mesmo processo dominante que ocorre no hospital, no tratamento de doentes em geral.

Se esse fato, porém, pode potencializar tal situação, ele não é suficiente para explicar a dominação do trabalho do médico. Há de se buscar suas causas nos outros instrumentos identificados: a prescrição médica e o hospital.

O saber que embasa essa prática é apoiado em importante recurso do trabalho do médico, que é a prescrição. Essa, ao se expandir até mesmo para procedimentos não complexos e nem sempre necessários, constitui em instrumento de dominação e de manutenção do poder de decisão.

Os dados obtidos revelaram também que essa assistência acontece unicamente em hospitais. É preciso lembrar que a transformação do hospital de local de recolhimento e exclusão para local de cura, no século XVIII, favoreceu a entrada dos médicos, o nascimento da clínica, a classificação das doenças e a rápida divisão técnica e social dos processos de trabalho nele existente, constituindo outro importante instrumento do trabalho do médico, talvez o principal ${ }^{(11)}$. Estabeleceu-se, assim, uma relação de estreita conivência entre instrumento (hospital) e agente (médico), onde o primeiro favorece a execução do modelo clínico de assistência pelo médico.
Por outro lado o médico também é instrumento do hospital, porque este precisa dele para desenvolver o trabalho assistencial.

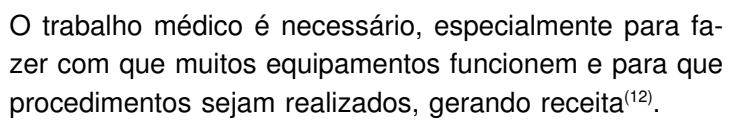

O trabalho médico é necessário, especialmente para fazer com que muitos equipamentos funcionem e para que procedimentos sejam realizados, gerando receita ${ }^{(12)}$.

Tal relação apresenta-se ainda mais forte com o crescimento da medicina de grupo e a incorporação do corpo clínico aberto pelos hospitais, que, numa inversão da relação meio-fim, possuem como seu verdadeiro cliente o profissional médico em vez da parturiente e, para mantê-lo, assimilam cada vez mais instrumentos de intervenção que facilitam o trabalho do médico, entre eles, o trabalho das enfermeiras. Ainda podemos acrescentar que

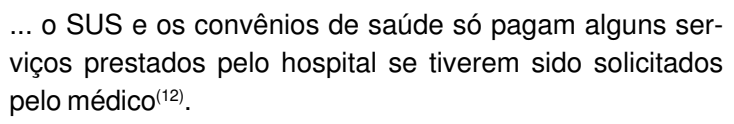

Tal situação, porém, não acontece descolada do contexto do desenvolvimento socioeconômico. A evolução acelerada do modelo clínico, expandindo sua apropriação até na assistência ao parto, ou seja, em pessoas não necessariamente doentes ou de risco, responde muito bem ao modo de produção capitalista, nesse particular, às indústrias de medicamentos e de equipamentos hospitalares, cujos produtos são absorvidos eminentemente pelos hospitais. Os hospitais têm assumido, de modo geral, um papel estratégico na manutenção das políticas de saúde no país e de produção e reprodução social ${ }^{(10)}$.

Associada à propaganda dos convênios de saúde, de que a melhor assistência depende da possibilidade de uso de toda tecnologia disponível, passa-se a idéia de que o melhor hospital é aquele mais equipado e com maiores recursos de intervenção, inclusive, na assistência ao parto.

Assim, estabelecem-se tais instrumentos como necessidades sociais, e não individuais. É possível até mesmo questionar se a finalidade do processo de assistência ao parto não visa atender antes as necessidades dos agentes e dos detentores dos instrumentos de trabalho, do que as das parturientes. É importante observar que

\begin{abstract}
... essas instituições se organizam sob regras rígidas que auxiliam no distanciamento dos trabalhadores das características humanas do seu objeto de trabalho, ao mesmo tempo que propiciam a defesa dos interesses corporativos em oposição à reflexão sobre a globalidade do processo assistencial(12).
\end{abstract}

\section{CONSIDERAÇÕES FINAIS}

Ainda que boa parte do progresso científico absorvido pelo hospital apresente condições reais de prevenir morbidade e mortalidade na assistência aos partos de risco, a contradição que se evidencia é que essas intercorrências 
não vêm diminuindo e, muitas vezes, são causadas justamente por esse mesmo progresso científico, através da generalização de sua necessidade e de seu abuso.

O oposto também é verdadeiro. Uma vez que tal assistência se faz através de diferentes modalidades de cobertura, obviamente que a qualidade, a distribuição e a utilização desses recursos não são iguais, negando-se a pseudo-aura de neutralidade desse modelo, ainda quando aplicados, em todas as circunstâncias, o mesmo conhecimento científico e as mesmas técnicas que o embasam.

O clímax do abuso de intervenções se traduz na quantidade excessiva de partos por cesárea. Além disso, é preciso lembrar que tal intervenção constitui instrumento de lucro tanto para hospitais quanto para médicos, por ser mais rápida e favorecer maior número de atendimentos. Isso também é estimulado pelo tipo de pagamento, por unidade de assistência.

As contradições de tais situações, todavia, já não se deixam ocultar. Além dos resultados muito aquém dos desejados, os custos exorbitantes desse modo de assistência fazem com que os próprios órgãos que o financiam e estimulam busquem, ao mesmo tempo, controlá-los. Do lado dos convênios privados de planos e seguros de saúde, o poder de decisão dos médicos chega até um limite, quando, para determinados procedimentos, precisam solicitar autori- zação dos planos de saúde dos clientes. Revela-se, assim, a pseudo-autonomia desses profissionais. Do lado do SUS, novas políticas, conforme já evidenciado, vêm sendo determinadas, entre elas, a mudança de instrumentos de trabalho, como novos locais de assistência, valorização do processo de trabalho de outros profissionais, como a enfermeira obstétrica, e pagamento semelhante para partos normais e para cesárea.

Tais mudanças, por si só, não são suficientes para a superação do atual modelo. Nada impede que os novos locais de prática e os novos agentes continuem a mantêlo. É preciso que se tornem cada vez mais evidentes, e com a maior freqüência possível, suas contradições e limitações.

Neste estudo, verificou-se, então, que a assistência ao parto em Londrina se dá sob o mesmo modelo de assistência à doença. Mas apresenta sua singularidade, uma vez que, na maioria dos casos de partos, as pessoas são sadias e não doentes.

Tal realidade desvela a fragilidade e a principal contradição desse modelo na assistência ao parto. Neste estudo, ela foi reforçada pela própria forma de fazer ciência que esse modelo engendra, ou seja, a ausência de consenso ou a dificuldade de fundamentar cientificamente a necessidade ou não dos procedimentos investigados.

\section{REFERÊNCIAS}

1. Diniz CSG. O que funciona e o que é justo: notas sobre a violência na assistência ao parto. In: Textos do Curso de Capacitação para o Atendimento a Mulheres em Situação de Violência. São Paulo; 1998.

2. Merhy EE. São Paulo de 1929 a 1948: a saúde pública como política. Os movimentos sanitários, os modelos tecnoassistenciais e a formação de políticas governamentais [tese]. Campinas: Departamento de Medicina Preventiva, Universidade Estadual de Campinas; 1991.

3. Organização Mundial da Saúde (OMS). Assistência ao parto normal: um guia prático. Brasília: OPAS/ USAID; 2000. [OMS/ SRF/ MSM/ 96.24]

4. Gonçalves RBM. Práticas de saúde: processo de trabalho e necessidade. São Paulo: [s.n.]; 1992.

5. Marx K. O capital: crítica da economia política. São Paulo: Nova Cultural; 1985. O processo de produção capital. v. 1, p. 149-63.

6. Heller A. Teoria de las necesidades en Marx. $2^{\mathrm{a}}$ ed. Barcelona: Ediciones Península; 1986.

7. Minayo MCS. O desafio do conhecimento: pesquisa qualitativa em saúde. $4^{a}$ ed. São Paulo: Hucitec; 1996. p. 197-247.

8. Bardin L. Análise de conteúdo. Lisboa: Edições 70; 1977.

9. Fiorin JL, Savioli FP. Para entender o texto: leitura e redação. $3^{a}$ ed. São Paulo: Ática; 1991.

10. Car MR. Da aparência à essência: a práxis assistencial dos trabalhadores da liga de hipertensão arterial [tese]. São Paulo: Escola de Enfermagem, Universidade de São Paulo; 1993.

11. Foucault M. Microfísica do poder. $5^{\mathrm{a}}$ ed. Rio de Janeiro: Graal; 1985. O nascimento do hospital; cap. 6, p. 103-4.

12. Pires D. A estrutura objetiva do trabalho em saúde. In: Leopardi MT, organizadora. Processo de trabalho em saúde: organização e subjetividade. Florianópolis: Programa de Pós Graduação em Enfermagem, Universidade Federal de Santa Catarina/Papa-Livros; 1999. cap. 2, p. 25-48. 